\begin{abstract}
HETEROCYCLES, Vol. 87, No. 5, 2013, pp. 967 - 990. @ 2013 The Japan Institute of Heterocyclic Chemistry
Received, 21st January, 2013, Accepted, 13th March, 2013, Published online, 25th March, 2013

DOI: 10.3987/REV-13-765

\section{THE PSEUDO-INTRAMOLECULAR PROCESS: A NOVEL SYNTHETIC METHOD FOR FUNCTIONALIZED HETEROCYCLIC COMPOUNDS}

\title{
Nagatoshi Nishiwaki*
}

School of Environmental Science and Engineering, Kochi University of Technology, Tosayamada, Kami, Kochi 782-8502, Japan

\begin{abstract}
A pseudo-intramolecular process has been developed. Compounds having both an acidic hydrogen and a functionality serve as substrates in the present method, and immediately form an ammonium salt after the addition of an amine. When the amine is liberated under mild equilibrium conditions, both the nucleophilic amine and the electrophilic substrate are in proximity and efficiently react under mild reaction conditions. Although the reaction actually concerns an intermolecular process, it proceeds as if it were an intramolecular process. Thus, this method forms a novel procedure for synthesizing polyfunctionalized compounds that are not easily available via alternative methods.
\end{abstract}

\section{INTRODUCTION}

Functionalized heterocyclic compounds constitute a large family of versatile organic compounds, which are used for versatile purposes such as medicines, agrochemicals, and fluorescent dyes. In order to prepare functionalized heterocyclic compounds, three methods are generally employed: (a) direct introduction of a functional group, (b) built-in methods that employ a functionalized building block, and (c) ring transformations of a cyclic compound (Scheme 1). Although direct method a is the most successful method to obtain the functionalized heterocyclic compounds, it is often also cumbersome as the scaffold framework is not always sufficiently reactive. Built-in method $\mathbf{b}$ involves the incorporation of a functional group to form the building block, and, indeed, is a powerful method in elaborate syntheses. Ring transformation $\mathbf{c}$ is an equally useful method for synthesizing complex skeletons that are not readily available by alternative methods. Although these methods are complementary to each other, new methods based on different concepts are need of the hour.

During our investigations on the functionalization of quinolone frameworks, we found a new concept that involves a pseudo-intramolecular process. The present review will introduce the discovery process of the 
reaction and its development into an efficient new method for the preparation of functionalized heterocyclic compounds under mild conditions.

(a) Direct approach
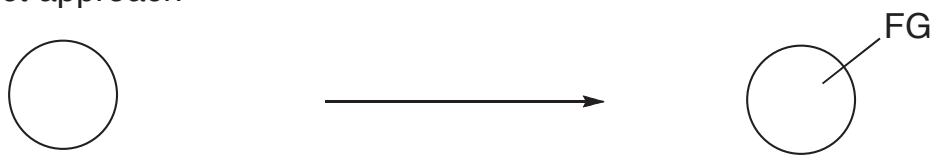

(b) Built-in method
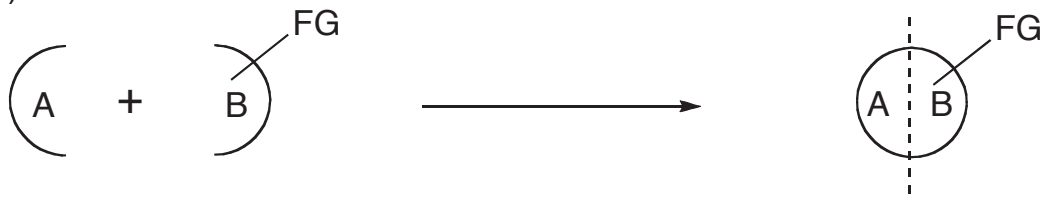

FG: functional group

(c) Ring transformation

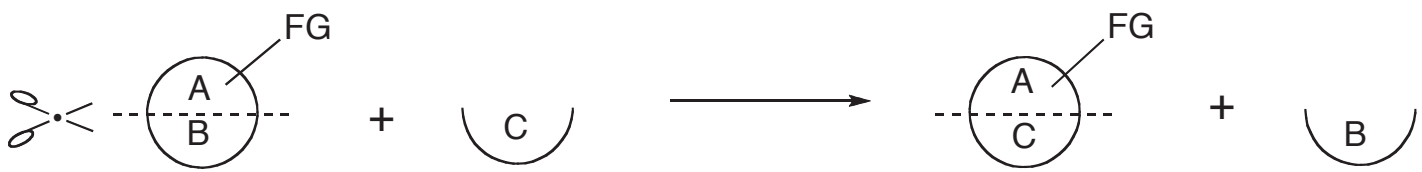

Scheme 1. Commonly used preparative methods for functionalized heterocycles.

\section{FUNCTIONALIZATION OF THE 1-METHYL-2-QUINOLONE FRAMEWORK}

1-Methyl-2-quinolone (MeQone) is a common partial structure in more than 300 quinoline alkaloids that are mainly isolated from the Rutaceae family of plants. ${ }^{1}$ Though naturally occurring MeQone derivatives show a wide range of biological activities and are thus of onterest in current research, ${ }^{2}$ attention is now being focused on unnatural MeQones because of their pharmacological and physiological advantages. However, it is not easy to functionalize the MeQone framework because of slight aromaticity of the pyridone moiety; hence, new synthesis and functionalization methods, involving simple experimental manipulations under mild conditions, need to be developed for the MeQone framework. ${ }^{3,4}$<smiles>CCOc1ccc(OCC)cc1</smiles><smiles>Cn1c(=O)c([N+](=O)[O-])cc2cc([N+](=O)[O-])cc([N+](=O)[O-])c21</smiles>

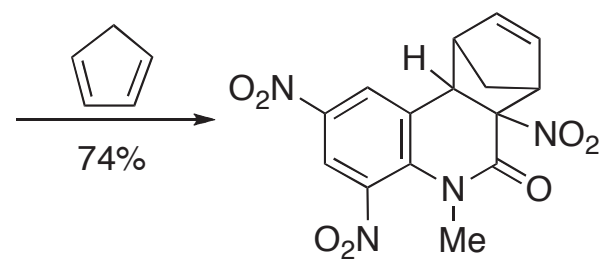

Scheme 2. Cycloadditions of trinitroquinolone (1).

Though most MeQone derivatives are only slightly reactive, 1-methyl-3,6,8-trinitro-2-quinolone (1) reveals a considerably high reactivity. As steric repulsion between the 1-methyl group and the 8-nitro groups distorts the coplanarity of the MeQone framework, ${ }^{5}$ the pyridone serves as a nitroalkene rather than an aromatic compound, facilitating the facile functionalization of the MeQone framework. Indeed, 
the nitroalkene moiety (at the 3 - and 4-positions) of $\mathbf{1}$ undergoes cycloaddition with electron-rich alkenes or dienes (Scheme 2). ${ }^{6}$ Furthermore, when $\mathbf{1}$ is treated with a nucleophile $(\mathrm{Nu})$, regioselective functionalization at the 4-position occurs, accompanied by elimination of the adjacent nitro group to afford 4-functionalized 6,8-dinitroquinolones (2), a process called cine-substitution. Though this present reaction, it is possible to employ versatile nucleophiles such as 1,3-dicarbonyl compounds, ${ }^{7}$ ketones, ${ }^{8}$ nitroalkanes, ${ }^{9}$ phenoxides, ${ }^{10}$ and amines ${ }^{11}$ (Scheme 3).

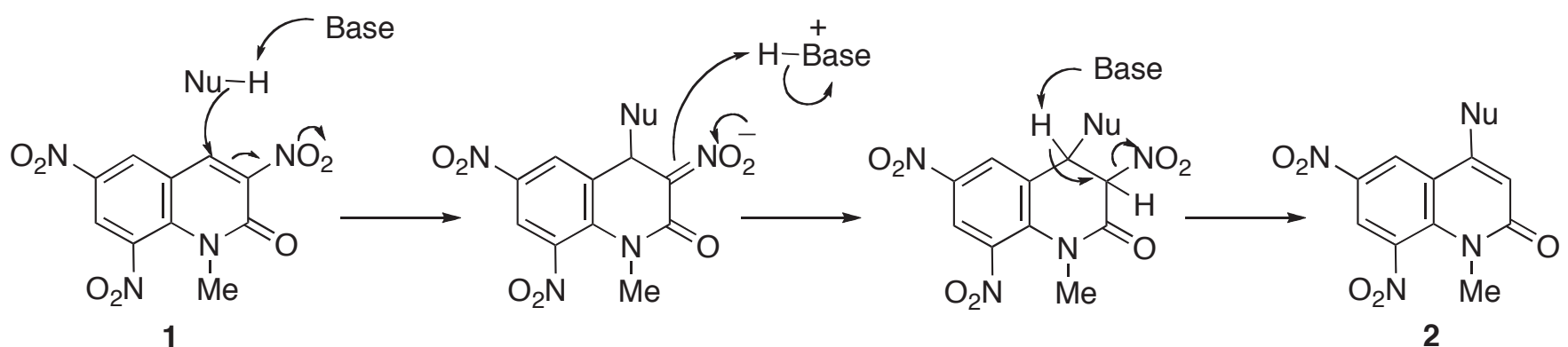

$\mathrm{Nu}-\mathrm{H}$ : 1,3-dicarbonyl compounds, ketones, nitroalkanes, phenols, amines

Scheme 3. cine-Substituion of 1 affording 4-functionalized 6,8-dinitroquinolone (2).

In the cine-substitution using 1,3-dicarbonyl compounds, diketones, keto esters, as well as diesters can be employed. Interestingly, thus-prepared $\alpha$-quinolyl- $\beta$-keto ester (2b) exhibited different reactivity compared to $\alpha$-quinolyl- $\beta$-diketone (2a) (Scheme 4 ). ${ }^{7}$ Though the diketone (2a) could be isolated by column chromatography and the pyrazolylquinolone (3) could be prepared by treatment of 2a with methylhydrazine (4a), the $\beta$-keto ester, on the other hand, was deacylated under the same conditions, suggests that introduction of an aryl group at the $\alpha$-position activates the acyl group of the $\beta$-keto ester.<smiles>CC(=O)/C(=C(/C)O)c1cc(=O)n(C)c2c([N+](=O)[O-])cc([N+](=O)[O-])cc12</smiles>

$2 a$<smiles>CCOC(=O)/C(=C(/C)O)c1cc(=O)n(C)c2c([N+](=O)[O-])cc([N+](=O)[O-])cc12</smiles>

$2 \mathbf{b}$
$+\mathrm{MeNHNH}_{2}$

$4 a$

$+\mathrm{MeNHNH}_{2}$

$4 a$

quant.<smiles>Cc1nn(C)c(C)c1-c1cc(=O)n(C)c2c([N+](=O)[O-])cc([N+](=O)[O-])cc12</smiles>

3<smiles>CCOC(=O)Cc1cc(=O)n(C)c2c([N+](=O)[O-])cc([N+](=O)[O-])cc12</smiles>

Scheme 4. Different reactivities observed for $\alpha$-quinolyl $\beta$-diketone (2a) and $\beta$-keto ester (2b). 


\section{3. $\alpha$-ARYLATION OF $\beta$-KETO ESTERS AND $\beta$-DIKETONE}

Compared to $\alpha$-aryl- $\beta$-diketones, ${ }^{12} \alpha$-aryl- $\beta$-keto esters cannot always efficiently be prepared, which might be because of the instability of the acyl group. Indeed, the preparation of $\alpha$-aryl- $\beta$-keto esters using keto esters and aryl halides generally suffers from deacylation of the products. ${ }^{13}$ Because the above experiments unequivocally indicated that the acyl group of keto ester is surely activated by an $\alpha$-aryl group, we employed 2,4-dinitrophenyl (DNP) moiety as an activating group. The DNP group was readily introduced by nucleophilic substitution of sodium enolate of ethyl acetoacetate (EAA-Na) with 1-chloro-2,4-dinitrobenzene (DNP-Cl). Arylated acetylacetone (AA-DNP) was similarly prepared upon the treatment of sodium enolate of acetylacetone (AA-Na) with DNP-Cl. On the other hand, under the same conditions, introduction of the DNP group into diethyl acetonedicarboxylate (DEAD-H) afforded a complex mixture, presumably because of the reactivity of multiple methylene groups. This problem was addressed by using triethylamine as a base (Scheme 5). The ${ }^{1} \mathrm{H}$ NMR data indicated that the prepared EAA-DNP, AA-DNP, and DEAD-DNP were present in only the enol forms only. ${ }^{14,15}$

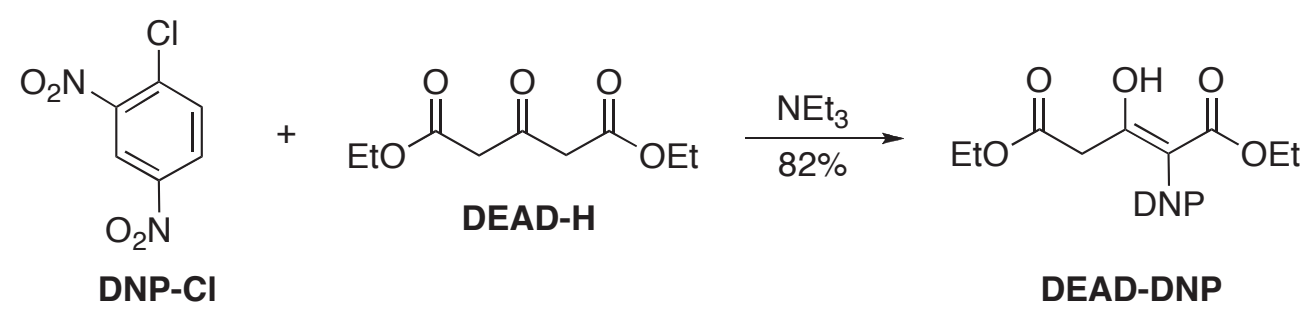

Scheme 5. $\alpha$-Arylation of $\beta$-keto ester DEAD-H with DNP-Cl, using triethylamine as a base.

\section{TRANSACYLATION OF EAA-DNP OR AA-DNP WITH PROPYLAMINE ${ }^{16}$}

When EAA-DNP was allowed to react with propylamine (5a) in chloroform, transacylation efficiently proceeded to afford $N$-propylacetamide (7a) and ethyl 2,4-dinitrophenylacetate (8) in quantitative yield. On the other hand, incubation of EAA-H with 5a under the same conditions did not lead to product formation, indicating that the acyl group was indeed activated by the DNP group. In the presented transacylation, ethanol as well as acetonitrile could be employed as the solvent.

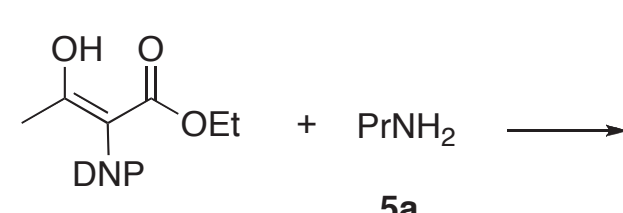

EAA-DNP

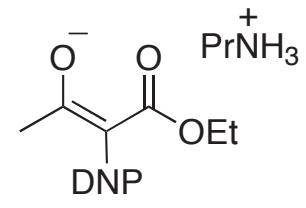

$6 a$

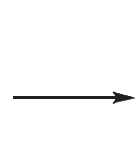

Scheme 6. Transacylation of EAA-DNP with propylamine (5a). 
In order to further study the reaction, transacylation was monitored with ${ }^{1} \mathrm{H}$ NMR. When propylamine (5a) was added to a solution of EAA-DNP in deuterated chloroform, ammonium enolate (6a) immediately formed. When the signals corresponding to $\mathbf{6 a}$ decreased, those of transacylated products (7a and 8) also gradually increased, without forming any detectable by-products (Scheme 6). Although the retro-Claisen condensation is a conventional reaction in organic chemistry, it still remains an important protocol in elaborate syntheses. ${ }^{17}$ Though this method usually requires activation by metal species or strong base, the present transacylation reaction efficiently proceeds under mild conditions without involving the use of any activating agent.

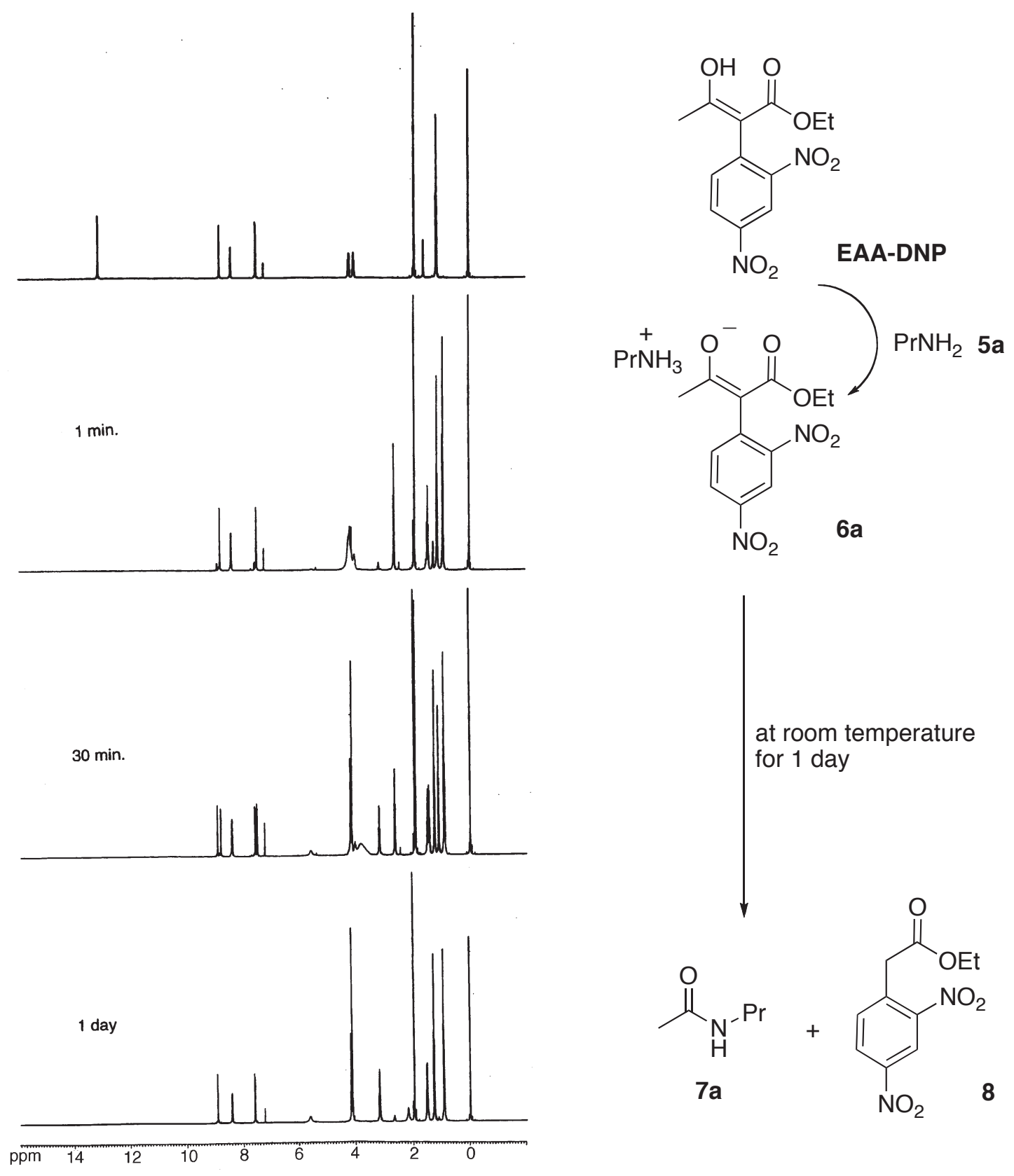

Figure 1. Monitoring the transacylation of EAA-DNP with propylamine (5a) by ${ }^{1} \mathrm{H}$ NMR. 
Similar transacylation was observed in the reaction of AA-DNP with 5a, although the reaction rate was considerably lower than that of EAA-DNP with 5a (75\% conversion after 5 d). The lower reactivity enabled the isolation of $\mathbf{2 a}$ and AA-DNP by column chromatography, indicating that the activated acyl groups of $\alpha$-aryl- $\beta$-keto esters can be used in the organic synthesis.

\section{TRANSACYLATION OF $\alpha$-ARYL- $\beta$-KETO ESTERS WITH AMINES ${ }^{16}$}

Transacylation using $\alpha$-aryl- $\beta$-keto esters was also applicable to amines other than 5a (Table 1). This reaction was considerably affected by the steric bulk of amines. During the reaction of EAA-DNP with propylamine (5a) at room temperature, $90 \%$ of $\mathbf{6 a}$ was consumed within $4 \mathrm{~h}$. Although transacylation of EAA-DNP with isopropylamine (5b) proceeded at room temperature to quantitatively afford the corresponding products ( $\mathbf{7 b}$ and $\mathbf{8}$ ), $15 \mathrm{~h}$ reaction time was needed to obtain $90 \%$ conversion. In the case of tert-butylamine (5c), the formation of ammonium enolate $\mathbf{6 c}$ was confirmed, but subsequent transacylation did not proceed, even not at $140{ }^{\circ} \mathrm{C}$ in a sealed tube.

Table 1. Transacylation of EAA-DNP or DEAD-DNP with various amines (5).<smiles>[R]C/C(O)=C(\[NH3+])C(=O)OCC</smiles>

EAA-DNP or DEAD-DNP<smiles>[R]CC(=O)N[13CH3]</smiles>

7 or 9
8

\begin{tabular}{|c|c|c|c|c|}
\hline $\mathrm{R}$ & $\mathrm{R}^{\prime}$ & Temp. $/{ }^{\circ} \mathrm{C}$ & Product & Yield / \% \\
\hline $\mathrm{H}$ & $\operatorname{Pr}$ & $\mathrm{rt}$ & $7 \mathbf{a}$ & quant. \\
\hline $\mathrm{H}$ & $i$-Pr & $\mathrm{rt}$ & $7 b$ & quant. \\
\hline $\mathrm{H}$ & $t-\mathrm{Bu}$ & $140^{a}$ & $7 c$ & 0 \\
\hline COOEt & $\operatorname{Pr}$ & $\mathrm{rt}$ & $9 a$ & quant. \\
\hline COOEt & $i-\operatorname{Pr}$ & 62 & $9 b$ & quant. \\
\hline COOEt & $t-\mathrm{Bu}$ & $62^{b}$ & $9 c$ & quant. \\
\hline $\mathrm{H}$ & $\mathrm{Ph}$ & $80^{a}$ & $7 e$ & 0 \\
\hline $\mathrm{H}$ & $\mathrm{Ph}$ & $80^{a, c}$ & $7 e$ & 77 \\
\hline COOEt & $\mathrm{Ph}$ & 62 & $9 e$ & trace \\
\hline COOEt & $\mathrm{Ph}$ & $62^{b, c}$ & $9 e$ & quant. \\
\hline COOEt & $p-\mathrm{NO}_{2} \mathrm{C}_{6} \mathrm{H}_{4}$ & $62^{c}$ & $9 \mathrm{~g}$ & trace \\
\hline COOEt & $p-\mathrm{MeOC}_{6} \mathrm{H}_{4}$ & $\mathrm{rt}$ & $9 h$ & quant. \\
\hline
\end{tabular}

${ }^{a}$ In a sealed tube. ${ }^{b} 7$ days. ${ }^{c}$ In the presence of 1 equiv. of $\mathrm{NEt}_{3}$. 
Susceptibility of transacylation reactions to the steric bulk of $\mathbf{5}$ was estimated by a competition reaction (Table 2). This reaction precisely recognized the presence of a methyl group at the $\alpha$-position of the amino group; the different positions of a methyl group between the $\alpha$ - and the $\beta$-positions were also effectively distinguished. The presence of a methyl group at the $\beta$-position was also recognized, although the selectivity was lowered.

Table 2. Competitive transacylation upon incubation with two types of amine.
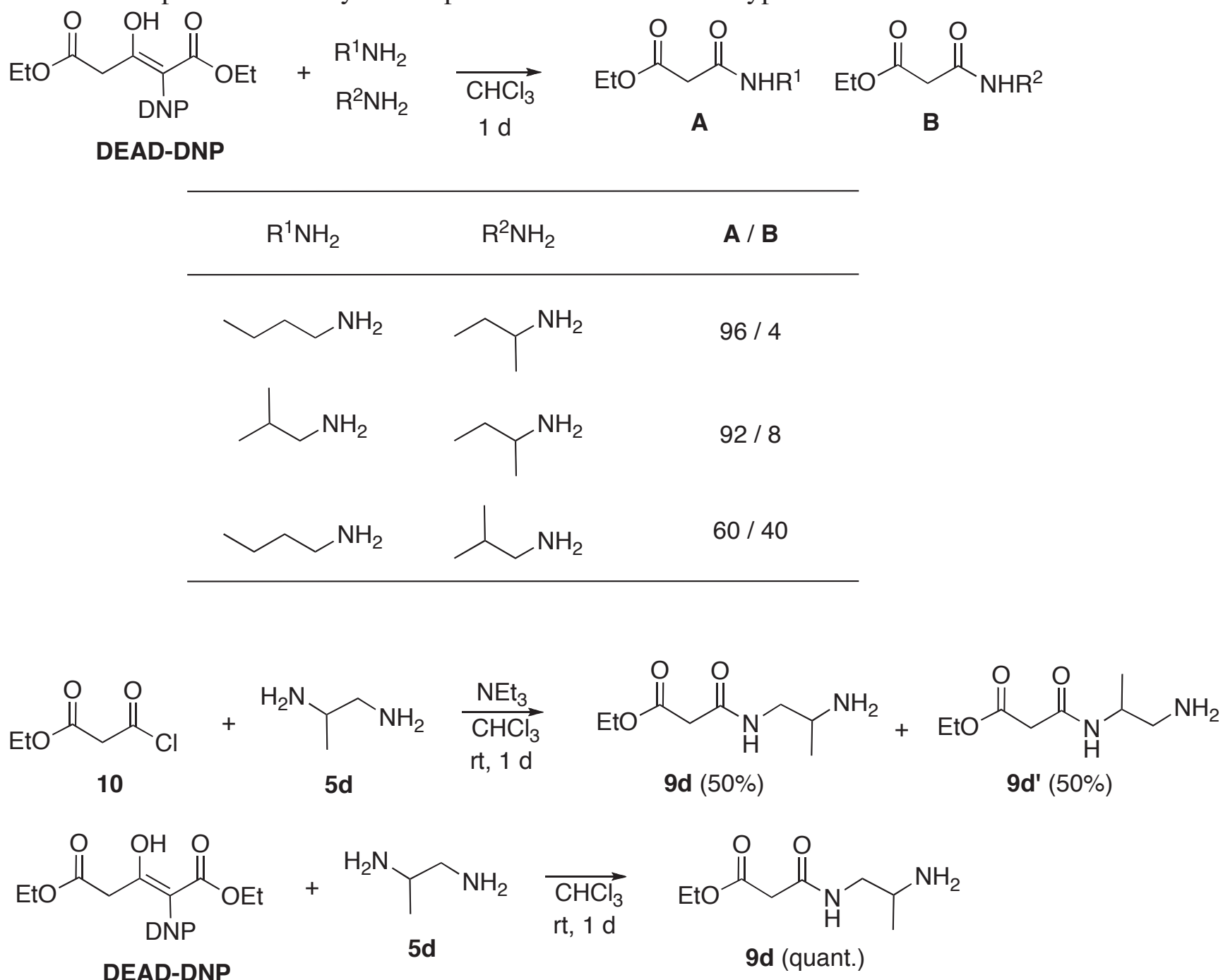

Scheme 7. Regioselective acylation of diamine (5d) by DEAD-DNP-mediated transacylation.

Because unsymmetrical malonic acid derivatives $(\mathbf{9})^{18}$ were easily obtained, transacylation using DEAD-DNP exhibited a higher synthetic utility as compared to that using EAA-DNP. Because the acyl group of DEAD-DNP is activated by an electron-withdrawing ethoxycarbonyl group, it could be transferred to tert-butylamine (5c) under high-temperature conditions (Table 1). As observed for EAA-DNP, the transacylation of DEAD-DNP was sensitive to the steric bulk of the amines used, 
enabling regioselective acylation of 1,2-diaminopropane (5d). Hence, it should be noted that the acylation of $\mathbf{5 d}$ with commercially available ethoxymalonyl chloride $(\mathbf{1 0})^{19}$ cannot distinguish between the different environments of the two amino groups, and triethylamine should be added in order to trap the generated acid. On the other hand, DEAD-DNP exclusively acrylated the terminal amino group to afford 9d without protecting the internal amino group in the absence of base (Scheme 7).

When EAA-DNP was allowed to react with aniline (5e), no anilinium enolate (6e) was formed because of its low basicity, not even when the reaction mixture was heated. The observed inactivity was overcome by adding triethylamine to the reaction mixture, thereby converting EAA-DNP into triethylammonium enolate (6f), although heating and longer reaction time were required for transacylation. During the reaction of DEAD-DNP with several aniline derivatives, a remarkable substituent effect was observed; while the starting $p$-nitroaniline (5g) was recovered, even when the mixture was heated in the presence of triethylamine, $p$-methoxyaniline (5h) effectively reacted at room temperature in the absence of triethylamine to afford amide ester (9h) (Table 1). These experimental results indicate that the initial formation of the ammonium enolate is crucial for efficient transacylation.

\section{TRANSACYLATION OF $\alpha$-ARYL- $\beta$-KETO ESTERS WITH ALCOHOLS}

Under harsher conditions, the less nucleophilic and less basic ethanol (11i) also reacted with EAA-DNP in the presence of triethylamine, while $O$-acylation proceeded without amine protecting group when 2-(tert-butylamino)ethanol (11j) was treated with EAA-DNP (Scheme 8). It is noteworthy that the latter reaction rate was considerably higher than that of the former in the presence of triethylamine. In the case of $\mathbf{1 1} \mathbf{j}$, formation of ammonium enolate $\mathbf{6} \mathbf{j}$ is considered to facilitate the approach of the hydroxy group to the EAA moiety, while, at the same time, the sterically hindered tert-butyl group prevents the reaction of the amino group with the EAA moiety.<smiles>CCOC(=O)C([NH3+])=C(C)O</smiles>

EAA-DNP<smiles>CCOC(=O)C([NH3+])=C(C)O</smiles>

EAA-DNP

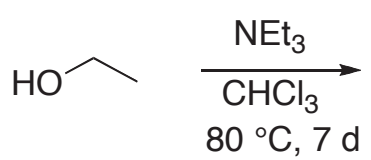

$11 \mathbf{i}$<smiles>CCOC(C)=O</smiles>

$63 \%$ in a sealed tube<smiles>OCCNBr</smiles>

11j<smiles>C=CC</smiles>
$80{ }^{\circ} \mathrm{C}, 0.3 \mathrm{~d}$ in a sealed tube<smiles>CC(=O)OCCN[Mg]</smiles><smiles>CCOC(=O)C([NH3+])=C(C)[O-]</smiles>

6j

Scheme 8. Chemoselective transacylation of alcohols without protecting amino group. 


\section{A PLAUSIBLE REACTION MECHANISM OF TRANSACYLATION}

On the basis of the above experimental facts, a plausible mechanism of the present reaction is as follows (Scheme 9). Because of steric repulsion, the EAA and DNP moieties in the keto ester are tilted with respect to each other at an angle of ca. $60^{\circ} .{ }^{15}$ When a sterically hindered substituent is introduced at the $\alpha$-position of the carbonyl group, only the keto form is destabilized giving rise to a stable enol. ${ }^{20}$ Indeed, only signals corresponding to the enol form were observed in the ${ }^{1} \mathrm{H}$ NMR of EAA-DNP and DEAD-DNP. In addition, introduction of the DNP group into EAA-H increases its acidity by approximately 7 orders of magnitude, making EAA-DNP a stronger acid than acetic acid. ${ }^{15,21}$ Hence, upon addition of amines, $\alpha$-aryl- $\beta$-keto esters are immediately converted to the corresponding ammonium enolates (6) accompanied by fission of the intramolecular hydrogen bond. Formation of the keto form (12) under equilibrium conditions brings the nucleophile and electrophile (amine (5) and $\mathbf{1 2}$ in Scheme 9) in proximity, and this "intimate pair" effect then results in quantitative transacylation under mild conditions. During the nucleophilic substitution of $\mathbf{1 2}$ with amine (5), the benzene ring rotates to attain coplanarity with the adjacent carbonyl group, which assists in the elimination of the transacylated product. The steric congestion of this "intimate pair" is responsible for the sensitivity of the reaction to the bulkiness of the nucleophile, thus enabling regio- and chemoselective reactions; a second important factor is the equilibrium between $\mathbf{6}$ and 12. The estimated difference of heat of formation between the keto and the enol forms of EAA-DNP are $35.77 \mathrm{~kJ} / \mathrm{mol}$ and AA- DNP are $39.16 \mathrm{~kJ} / \mathrm{mol}$, respectively. Because a more stable enol form cannot easily convert to the corresponding keto form, transacylation using AA-DNP is considered to be slower than that using EAA-DNP.
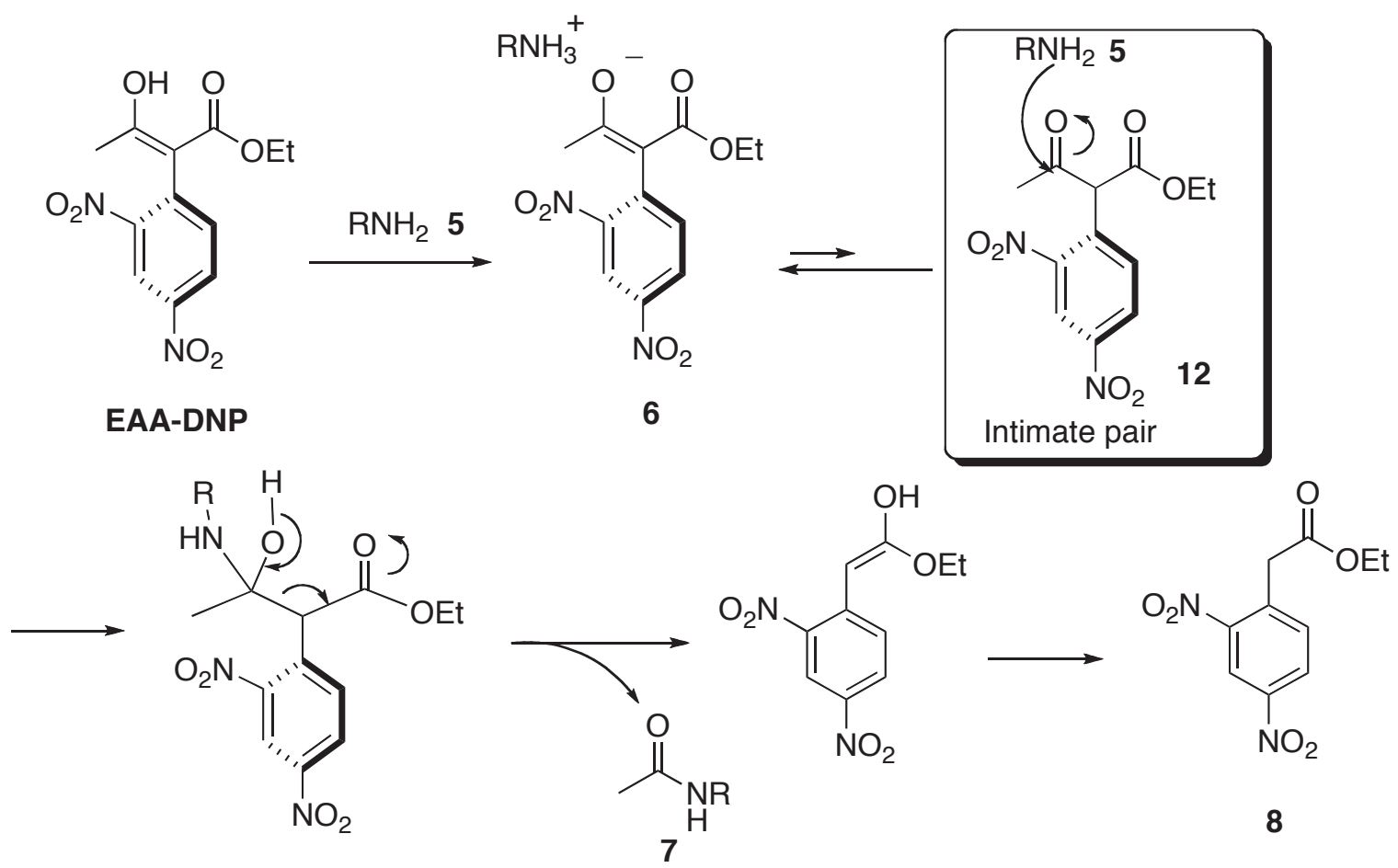

Scheme 9. A plausible mechanism of transacylation reaction of keto ester with amines. 
In the case of less basic nucleophiles such as aniline (5e) and ethanol (11i), the addition of triethylamine was necessary for the conversion of EAA-DNP to the corresponding ammonium enolates. However, extended reaction times and a higher reaction temperature were required because of the absence of the intimate pair effect in the intermolecular process. Even though the mixture was heated with triethylamine, the reaction involving aniline was quite slow. On the other hand, the reaction with $p$-methoxyaniline (5h) efficiently proceeded at room temperature in the absence of triethylamine. $O$-Acylation of aminoethanol (11j) was rather fast because of the formation of the intimate pair.

\section{THE CONCEPT OF PSEUDO-INTRAMOLECULAR PROCESS}

Transacylation efficiently proceeds via the intimate pair intermediate, which is reminiscent of an intramolecular process even though the reaction actually concerns an intermolecular process. Hence, we named the present reaction pseudo-intramolecular. The general concept of the pseudo-intramolecular process is illustrated in Scheme 10. First, an acidic hydrogen attracts an amine by forming an ammonium salt. When this amine is liberated under equilibrium, the nucleophilic amine and the electrophilic substrate are situated in proximity, forming an intimate pair. This spatial proximity enables an efficient reaction, which even though it actually concerns in an intermolecular process, proceeds similar to an intramolecular process.

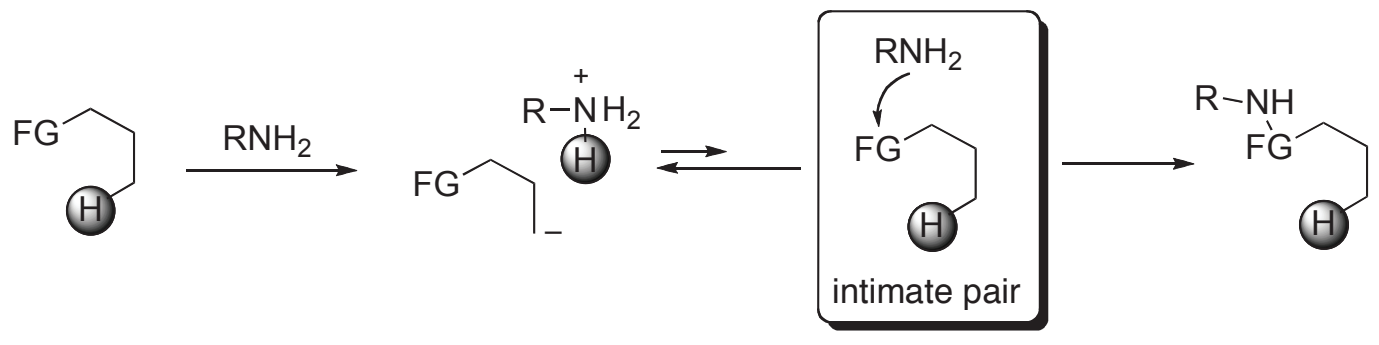

Scheme 10. Concept of "pseudo-intramolecular process".

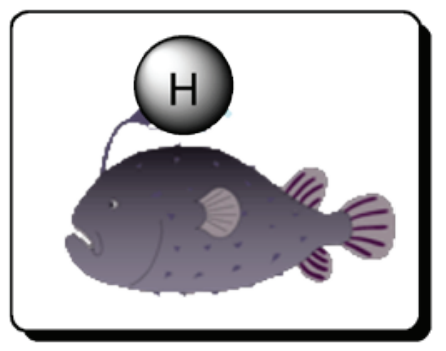

The present reaction process requires a substrate that has an acidic hydrogen as well as a second functionality. The acidic hydrogen atom functions as a lure for attracting the amine, followed by an attack by the functional group, which is reminiscent to the way in which a football fish attracts its prey. With respect to $\alpha$-aryl- $\beta$-keto esters, the acidity of the hydrogen at the geminal position is increased by the aryl group's steric bulk. Therefore, we considered the electron-withdrawing nitro group to be useful for substrate activation. 


\section{TRANSACYLATION USING $\alpha$-NITRO- $\beta$-KETO ESTERS ${ }^{22}$}

Nitration of $\beta$-keto esters was readily accomplished by Laikhter's method ${ }^{23}$ using two-phase reaction

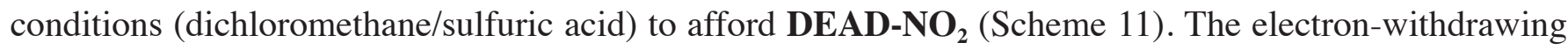
properties of the nitro group of DEAD-NO $\mathrm{N}_{2}$ prevent the formation of polynitrated keto esters during nitration of DEAD-H. Because only nitrated compound DEAD-NO $\mathbf{N}_{2}$ dissolved in the organic layer, it could easily be isolated from the reaction mixture by separating the organic layer after nitration.

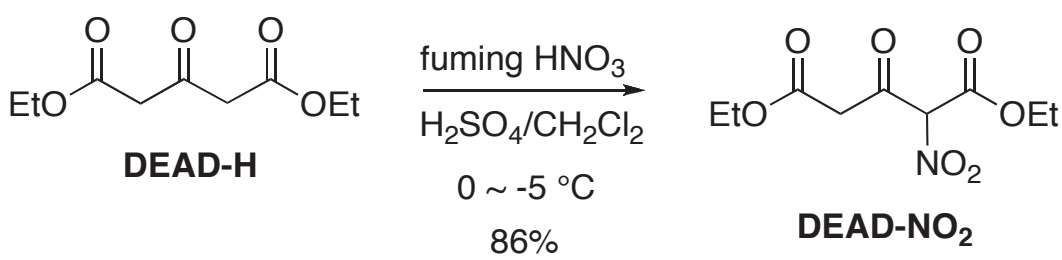

Scheme 11. Nitration of DEAD-H by Laikhter's method.

When a mixture of the resulting 2-nitro-3-oxoester (DEAD-NO $\mathbf{~}_{2}$ ) and propylamine (5a) in dichloromethane was stirred at room temperature for $1 \mathrm{~d}$, nucleophilic substitution of the central carbonyl group quantitatively proceeded to give amide ester (9a) along with ethyl nitroacetate (13). The same DEAD-NO $\mathbf{N}_{2}$ could be employed in subsequent reactions without requiring any further increase in its concentration or purification. The transacylation reaction was similarly effective when bulkier amines (5b) and (5c) were employed (Table 3).

Table 3. Transacylation of DEAD-NO $\mathbf{N}_{2}$ with amines or alcohols.

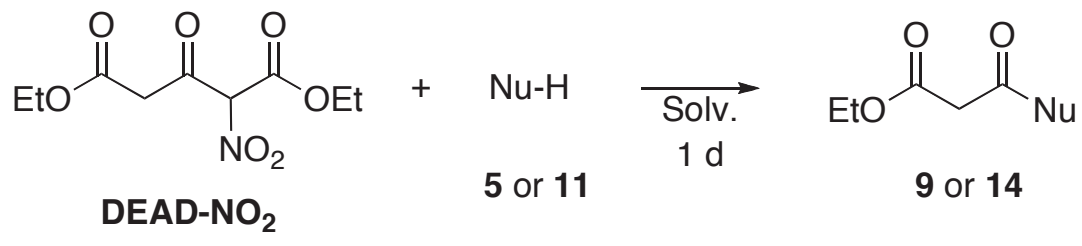

\begin{tabular}{cccccc}
\hline $\mathrm{Nu}-\mathrm{H}$ & & Solv. & Temp. $/{ }^{\circ} \mathrm{C}$ & Product & Yield $/ \%$ \\
\hline $\mathrm{PrNH}_{2}$ & $\mathbf{5 a}$ & $\mathrm{CH}_{2} \mathrm{Cl}_{2}$ & $\mathrm{rt}$ & $\mathbf{9 a}$ & quant. \\
$i-\mathrm{PrNH}_{2}$ & $\mathbf{5 b}$ & $\mathrm{CH}_{2} \mathrm{Cl}_{2}$ & 40 & $\mathbf{9 b}$ & 62 \\
$t-\mathrm{BuNH}_{2}$ & $\mathbf{5 c}$ & $\mathrm{CH}_{2} \mathrm{Cl}_{2}$ & 40 & $\mathbf{9 c}$ & 41 \\
$\mathrm{MeOH}^{2}$ & $\mathbf{1 1 k}$ & $\mathrm{MeOH}$ & $\mathrm{rt}$ & $\mathbf{1 4 k}$ & 92 \\
$\mathrm{MeOH}^{a}$ & $\mathbf{1 1 k}$ & $\mathrm{CHCl}_{3}$ & 60 & $\mathbf{1 4 k}$ & 89 \\
$i-\mathrm{PrOH}$ & $\mathbf{1 1 m}$ & $i-\mathrm{PrOH}$ & 65 & $\mathbf{1 4 m}$ & 59 \\
$t-\mathrm{BuOH}$ & $\mathbf{1 1 n}$ & $t-\mathrm{BuOH}$ & $80^{b, c}$ & $\mathbf{1 4 n}$ & 38 \\
\hline
\end{tabular}

${ }^{a}$ Five equivalents of $\mathrm{MeOH}$ were used. $^{b}$ Reaction time: 3 days. ${ }^{c} t$-BuOK was added. 
Because a strongly electron-withdrawing nitro group activates the adjacent carbonyl group more than the DNP group, alcohols could also be employed as nucleophiles. ${ }^{24}$ When a solution of DEAD-NO ${ }_{2}$ in methanol (11k) was stirred at room temperature, unsymmetrical diester (14k) was obtained in high yield. The amount of methanol (11k) could be decreased to 5 molar equivalents by conducting the reaction in a chloroform solution under reflux conditions (Table 3). In addition, sterically hindered isopropanol (11m) and tert-butyl alcohol (11n) could also be employed, yielding diesters (14m and 14n) in moderate yield, although the latter compound necessitated the addition of potassium tert-butoxide.

\section{STUDY ON REACTION MECHANISM}

To clarify the transacylation mechanism, we monitored the reactions of DEAD-NO $\mathbf{N}_{2}$ and propylamine /methanol at room temperature by ${ }^{1} \mathrm{HNMR}$ using chloroform- $d$ as the solvent. Initially, signals for the diastereotopic protons at the 4-position of DEAD-NO $\mathbf{N O}_{2}$ were observed separately. However, upon the addition of propylamine (5a), the signals instantaneously merged while those corresponding to the $N$-methylene protons of 5a shifted from 2.6 to $3.0 \mathrm{ppm}$. These changes indicated that the amine (5a) abstracts a hydrogen at the 2-position of DEAD-NO $\mathbf{N}_{2}$, forming ammonium nitronate (15a). The signals corresponding to $\mathbf{9 a}$ and $\mathbf{1 3}$ gradually increased while those of $\mathbf{1 5} \mathbf{a}$ decreased, leading to the complete consumption of 15a within $3 \mathrm{~h}$. However, upon the reaction of DEAD-NO $\mathbf{2}_{2}$ with methanol (11k), the diastereotopic methylene signals were stable, indicating that a nitronate $\mathbf{1 5 a}$ did not form. Indeed, $30 \mathrm{~h}$ of reaction time were required for the consumption of 15a. In summary, these results indicated that the former reaction proceeds via a pseudo-intramolecular process through the formation of ammonium nitronate (15); on the other hand, the latter reaction proceeds only slowly because of the sluggishness of the intermolecular process, in addition to the low nucleophilicity of methanol (11k).

Table 4. Comparison between the reactivity of aminoethanol (110) and ethanol (11p) with DEAD-NO .

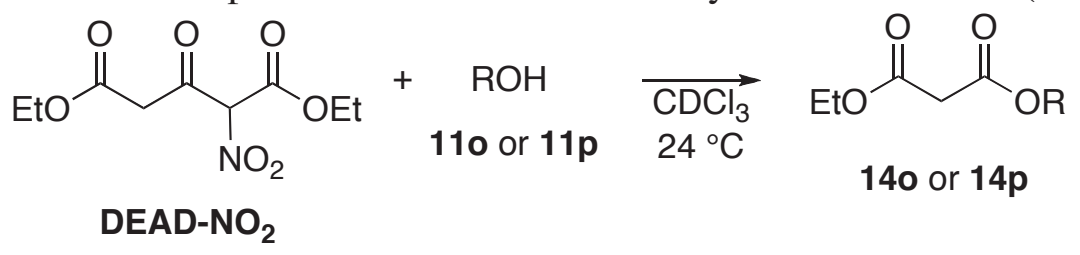

\begin{tabular}{cccc}
\hline $\mathrm{ROH}$ & Concentration / mM & Time / h & Yield / \% \\
\hline $\mathrm{Me}_{2} \mathrm{NCH}_{2} \mathrm{CH}_{2} \mathrm{OH}$ & 124 & 2 & 90 \\
$\mathrm{Me}_{2} \mathrm{NCH}_{2} \mathrm{CH}_{2} \mathrm{OH}$ & 62 & 2 & 90 \\
$\mathrm{EtOH}$ & 124 & 2 & 6 \\
$\mathrm{EtOH}$ & 124 & 6 & 17 \\
$\mathrm{EtOH}$ & 62 & 6 & 3 \\
\hline
\end{tabular}


To confirm the accelerating effect of intimate pair formation, we monitored the reaction of 2-dimethylaminoethanol (11o; $124 \mathrm{mM})$ and ethanol (11p; $124 \mathrm{mM})$ with DEAD-NO by ${ }^{1} \mathrm{H}$ NMR, using chloroform- $d$ as the solvent at $24{ }^{\circ} \mathrm{C}$. Both the nucleophiles underwent $O$-acylation with DEAD-NO $\mathbf{N O}_{2}$ give the corresponding diesters (14o and 14p). In the case of aminoethanol (11o), the respective salt (15o) immediately formed after the addition of 11o. A significant difference in the reactivity was observed between the alcohols (11o and 11p). Although the reaction of 110 with 13 afforded $\mathbf{1 4 0}$ in $90 \%$ yield after $2 \mathrm{~h}, \mathbf{1 4 p}$ was obtained in only $6 \%$ yield after the same reaction period. The reactivity of ethanol (11p) did not increase when triethylamine was added to the reaction mixture, supporting the assumption that the reaction of 110 proceeds via a pseudo-intramolecular process, in which an intimate pair is formed upon deprotonation of DEAD-NO $\mathbf{N}_{2}$ by the dimethylamino group (Table 4 and Scheme 12). Further experiments under diluted conditions allowed us to determine whether the reaction proceeded via a pseudo-intramolecular process or an intermolecular process. When the concentration of both DEAD-NO and $(11 \mathrm{p} ; 62 \mathrm{mM})$ were decreased to half their original value, the yield of $14 \mathrm{p}$ after $6 \mathrm{~h}$ substantially decreased from $17 \%$ to $3 \%$, suggesting that the reaction proceeds via an intermolecular mechanism. On the other hand, aminoalcohol $(\mathbf{1 1 0} ; 62 \mathrm{mM})$ was readily converted to 110 (90\% after $2 \mathrm{~h}$ ) despite being diluted, supporting the pseudo-intramolecular process.<smiles>CCOC(=O)CC(=O)C(C(=O)OCC)([N+](C)=O)[N+](=O)[O-]</smiles>

DEAD-NO<smiles>CCOC(=O)CC(=O)C(C(=O)OCC)=[N+]([O-])[O-]</smiles>

150<smiles>CCOC(=O)CC(C)(CCOCCN(C)C)C(C(=O)[O-])C(=O)OCC</smiles><smiles>CCOC(=O)CC(=O)OCCN(C)C</smiles>

Scheme 12. A plausible mechanism for the $O$-acylation of aminoethanol (110).

\section{1. $\alpha$-NITRO- $\delta$-KETO NITRILE}

So far, the transacylation reaction was shown to proceed via a pseudo-intramolecular process, enabling a highly efficient reaction under mild conditions. This observation prompted us to expand the concept to other types of syntheses. Because the substrate for the pseudo-intramolecular reaction requires an acidic hydrogen to recruit the amine as well as a second functional group, many compounds should exist that 
satisfy these criteria, where the molecular design and synthesis are not expected to be exceptionally difficult. Hence, it is anticipated that the pseudo-intramolecular process can be applied to general organic synthesis.

In the course of our study, we synthesized a considerable number of nitro compounds. The pyridinium salt of nitroisoxazolone (16), for example, revealed a versatile reactivity, allowing the preparation of polyfunctionalized compounds (Scheme 13). ${ }^{25-31} \alpha$-Nitro- $\delta$-keto nitrile (17) whose structure satisfies the two criteria for a substrates in the pseudo-intramolecular reaction, was easily prepared by the ring opening of pyridinium salt (16) followed by treatment with excess of acetone in one-pot. ${ }^{31}$ Here, we focus on the structural features of $\mathbf{1 7}$, and our attempts to synthesize polyfunctionalized heterocycles using the pseudo-intramolecular process.

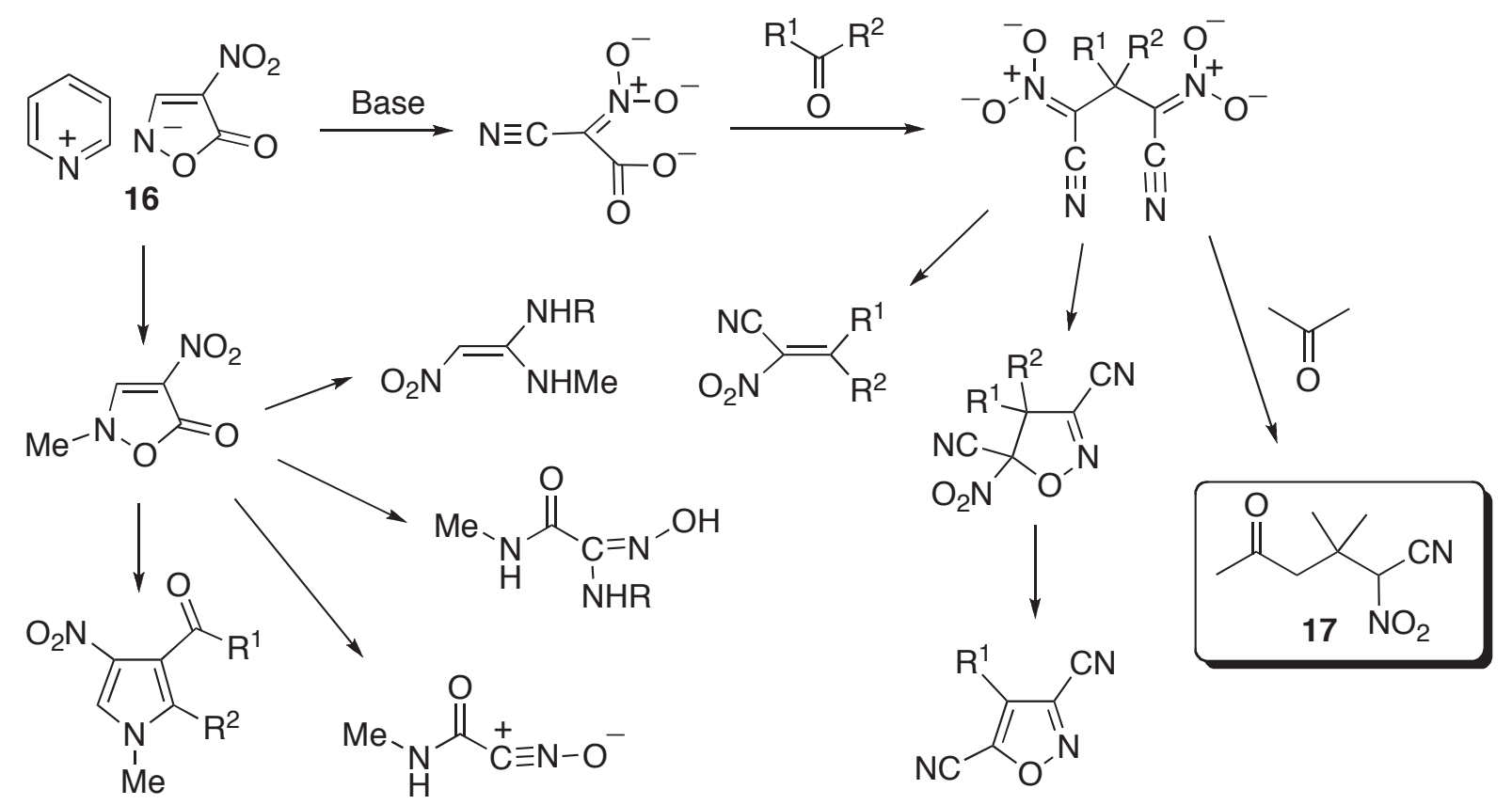

Scheme 13. Diverse reactivity of nitroisoxazolones.

\section{SYNTHESIS OF 1,4-DIHYDROPYRIDINES ${ }^{32}$}

Addition of propylamine (5a) to a solution of keto nitrile (17) in acetonitrile resulted in the quantitative formation of ammonium salt (18a), as indicated by a strong absorption of the cyano group in the IR spectrum, which is a typical feature of the $\alpha$-cyanonitronate framework. When a solution of 18a in acetonitrile was heated under reflux, 3-nitro-2-propylamino-1,4-dihydropyridine (19a) was isolated in $71 \%$ yield. Although the transacylation reaction gave no by-product, several unidentified products were formed during reaction. This presumably results from side reactions caused by the presence of multiple functionalities on keto nitrile (17). A plausible mechanism for the present pseudo-intramolecular reaction is illustrated in Scheme 14. Upon the heating of ammonium salt (18a), amine is expelled under equilibrium to give an intimate pair (20). The liberated amine then attacks the proximate cyano group, 
which then attacks the acyl group to form a six-membered ring. Subsequent dehydration and proton transfer form dihydropyridine (19a).

On the other hand, bulkier amines such as isopropylamine (5b), tert-butylamine (5c), and aniline (5e) did not result in cyclization. The high sensitivity to steric hindrance is because of the congestion around the reaction site of intimate pair (20). Insertion of a methylene group, which acts as a spacer between the bulky group and the amino functional group, facilitated the cyclization to afford dihydropyridines $(\mathbf{1 9 q}-\mathbf{u})$, (Table 5). Because frameworks that contain both donor and acceptor moieties are often found as partial structures of functional materials such as molecular electronic devices, chromophores, and nonlinear optics, ${ }^{33}$ the present reaction will supplement conventional methods for preparing 1,4-dihydropyridines.
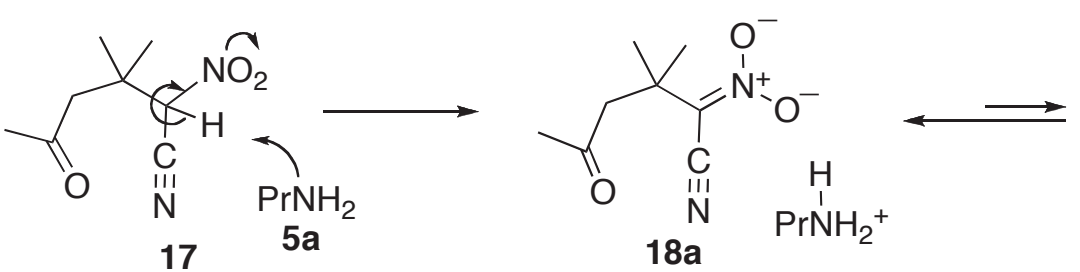

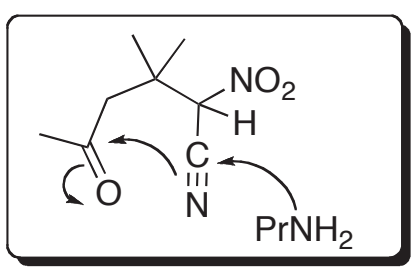

intimate pair 20<smiles>COC1C([NH+])=NC(C)(C)C(C(C)C)C1(C)C</smiles>

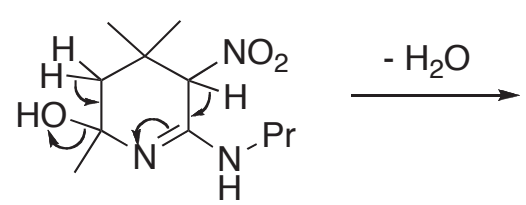<smiles>CCCNC1=C([N+](=O)[O-])C(C)(C)C=C(C)N1</smiles>

$19 a$

Table 5. Reactions of keto nitrile (17) with other amines (5).<smiles>CC(=O)CC(C)(C)C(C#N)C([NH3+])[N+](=O)[O-]</smiles>

\begin{tabular}{ccc}
\hline $\mathrm{R}$ & Product & Yield /\% \\
\hline $\mathrm{Et}_{-}-\mathrm{CH}_{2}-$ & $\mathbf{1 9 a}$ & 71 \\
$i-\mathrm{Pr}_{-} \mathrm{CH}_{2}-$ & $\mathbf{1 9 q}$ & 63 \\
$t-\mathrm{Bu}-\mathrm{CH}_{2}-$ & $\mathbf{1 9 r}$ & 48 \\
$c-\mathrm{Hex}-\mathrm{CH}_{2}-$ & $\mathbf{1 9}$ & 59 \\
$\mathrm{Ph}-\mathrm{CH}_{2}^{-}$ & $\mathbf{1 9 t}$ & 80 \\
$(\mathrm{MeO})_{2} \mathrm{CH}_{-}-\mathrm{CH}_{2-}$ & $\mathbf{1 9 u}$ & 74 \\
\hline
\end{tabular}




\section{SYNTHESIS OF DIAZEPINE ${ }^{34}$}

As stated above, $\alpha$-nitro- $\delta$-keto nitrile (17) exhibits multiple functionalities. When a dinucleophilic reagent is employed instead of monoamine, both nucleophilic and electrophilic sites remain within spatial proximity, even after the formation of the ammonium salt. These sites will readily react to afford a new framework. On the basis of this assumption, the reaction of keto nitrile (17) with various dinucleophilic hydrazines (4) was studied.

When keto nitrile (17) was allowed to react with unsubstituted hydrazine (4b) at room temperature in acetonitrile, diazepine (21) was obtained in 63\% yield. The key step in this reaction involves hydrazone formation via the pseudo-intramolecular process through the hydrazinium salt (22b) to afford hydrazone (23), which then undergoes ring closure by nucleophilic attack on the cyano group (Scheme 15). Interestingly, methylhydrazine (4a) exhibited a clearly different reactivity under the same reaction conditions, which was considerably more complicated, giving rise to an intractable mixture. A similarly complex reaction mixture was observed during the reaction of 17 with the bulky $t$-butylhydrazine $(\mathbf{4 c})$. In each case, the corresponding diazepines (24a and 24c) could possibly have been formed, yet isolation failed because of the instability of the compounds. In the case of the unsubstituted hydrazine (4b), diazepine (24b) could be converted to a stable form such as $\mathbf{2 1}$ by tautomerization (Scheme 15).
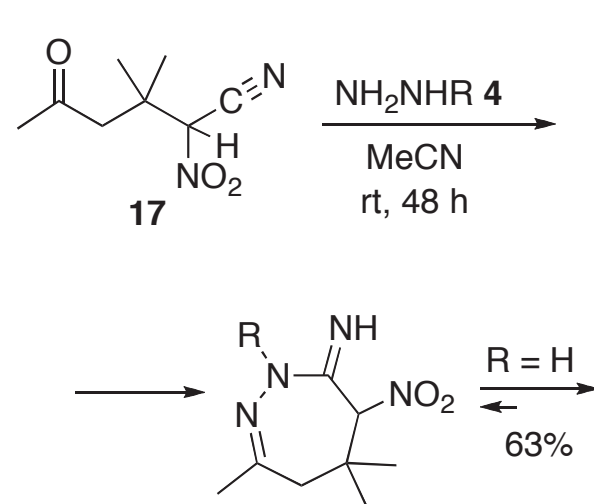

24

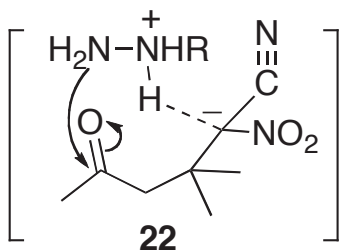

22<smiles>CC1=NN=C(N)C([N+](=O)[O-])C(C)(C)C1</smiles>

21

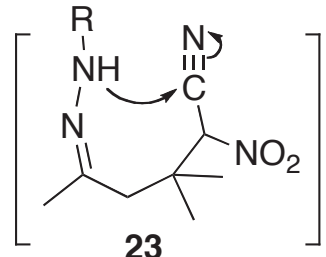

23

Scheme 15. Formation of diazepine (21) involving the pseudo-intramolecular hydrazonation.

During the present reaction, six-membered ring formation is also possible, as shown in Scheme 16. To elucidate a plausible reaction pathway, density functional theory (DFT) calculations for simplified model compound (25), bearing no methyl group at the $\beta$-position, were performed. Comparison of the activation energies of either transition state showed that the activation energy for the seven-membered ring is lower than that for the six-membered ring. Water plays an important role in the former mechanism; owing to the proximity of these functional groups, a water molecule interacts with both the cyano and the amino groups to undergo a water-assisted ring construction. 

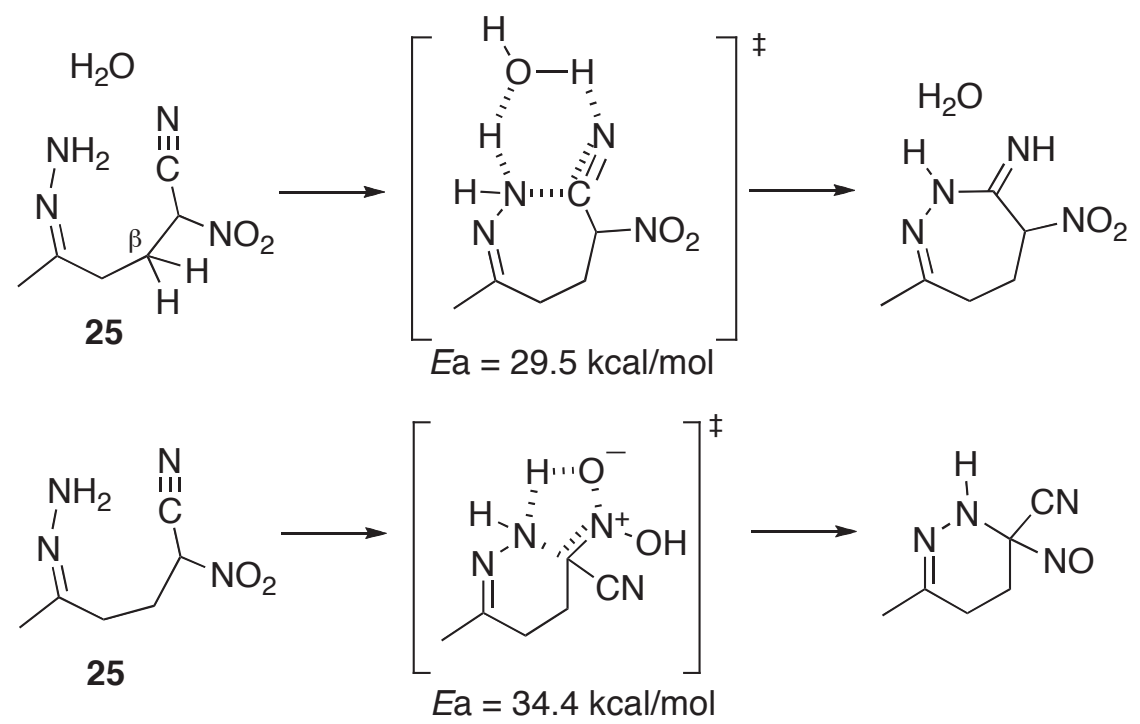

Scheme 16. Calculated activation energies $(\mathrm{Ea})$ for different ring-closure modes, as estimated by DFT calculations.

\section{SYNTHESIS OF PYRIDAZINES ${ }^{34}$}

Although formation of the intermediate hydrazone (such as 23) has been suggested, as illustrated in Scheme 15, the intermediates were generally too reactive to be isolated. Hence, we attempted the isolation of the hydrazones by using aromatic hydrazines. Indeed, the use of electron-deficient 4-nitrophenylhydrazine (4d) and 2,4-dinitrophenylhydrazine (4e) enabled to isolate the hydrazones (23d and 23e) in quantitative yields: both the compounds spontaneously precipitated from solution within $3 \mathrm{~h}$ of the addition of $\mathbf{4 d}$ and $\mathbf{4 e}$ to a solution of $\mathbf{1 7}$ (Scheme 17). When the isolated hydrazone (23d) in DMSO was left to stand at room temperature for $1 \mathrm{~d}$, a crystalline product was afforded, whose spectral data quite significantly differed from that expected for the corresponding diazepine, indicating the product to be pyridazine (26d) (Scheme 17). Using a similar procedure $\left(70{ }^{\circ} \mathrm{C}\right)$, 2,4-dinitrophenylhydrazone (23e) could be transformed to the pyridazine (26e) in $69 \%$ yield.

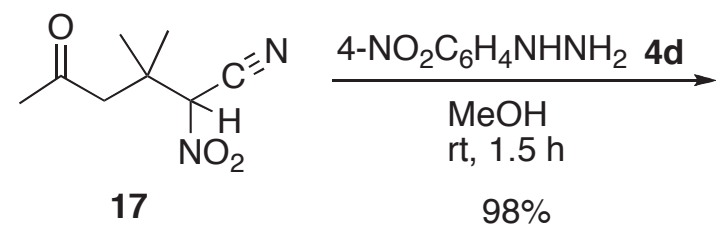

17<smiles>C/C(CC(C)(C)C(C#N)[N+](=O)[O-])=N/N=C\[N+](=O)[O-]</smiles>

23d

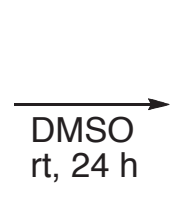

$86 \%$<smiles>CC1=NN(CC(=O)O[Na])C(C#N)(C#N)C(C)(C)C1</smiles>

26d

Scheme 17. Hydrazonation of $\alpha$-nitro- $\delta$-keto nitrile (17) and subsequent ring closure to afford pyridazines (26d). 
It was observed that the pseudo-intramolecular hydrazonation of keto nitrile (17) afforded hydrazones (23) upon treatment with hydrazines (4), displaying a distinct reactivity depending on the substituent. These differences are attributed to the inherent basicities and nucleophilicities of the hydrazones. For the unsubstituted and alkyl substituted hydrazones $(\mathbf{2 3 a}-\mathbf{c})$, the nucleophilicity of nitrogens led to quick ring closure, affording the diazepines $(\mathbf{2 4 a - c})$, from which $\mathbf{2 4 b}$ could be converted to the stable $\mathbf{2 1}$. For aromatic hydrazones (23d and $\mathbf{2 3 e}$ ), the aromatic ring bearing an electron-withdrawing substituent stabilizes the hydrazone and decreases the nucleophilicity of the neighboring nitrogen. When these hydrazones were heated in a polar solvent, tautomerization of the nitro group occurred, affording nitronic acids (27e and $\mathbf{2 7 f}$ ); the $\alpha$-carbon of the cyano group was sufficiently electrophilic to allow attack by the anilino nitrogen to form the pyridazine frameworks of $\mathbf{2 6} \mathbf{d}$ and $26 \mathbf{e}$. DFT calculations (B3LYP/6-31++G*) on model compounds (28 and 29) showed the electrophilicity of the nitronic acid carbon $\left(\mathrm{C}_{\mathrm{a}}\right)$ to be considerably higher than that of the cyano group, which is in good agreement with the experimental results (Figure 2).

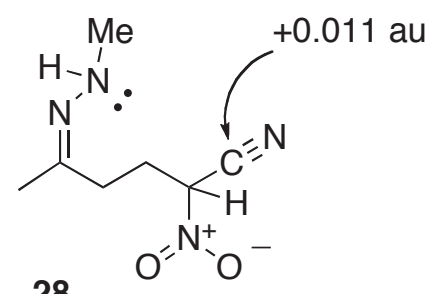

28

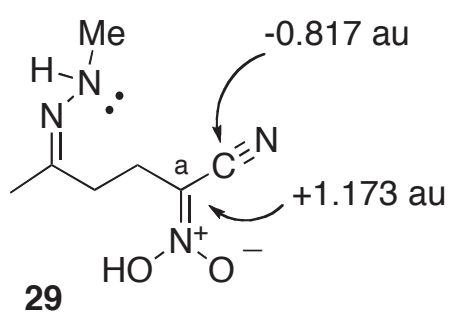

Figure 2. Electron density of model compounds (28 and 29), as estimated by DFT calculations.

\section{TANDEM BICYCLIZATION USING DIAMINES ${ }^{35}$}

Judging on the abovementioned results obtained from the use of hydrazines, we considered that pseudo-intramolecular imination should unequivocally proceed at the carbonyl group when diamines such as 30 were employed. As illustrated in Scheme 18 for 1,2-diaminoethane (30a), the reaction is initiated by the deprotonation of the $\alpha$-carbon of $\delta$-keto nitrile (17) to afford ammonium salt (31a), which brings the two reactants, (17 and 31a) in proximity, giving rise to pseudo-intramolecular imination and yielding zwitterionic imine (32a). When imine (32a) is heated, a small quantity of amine (33a) is formed under the equilibrium conditions, and the nucleophilic character of the amino group and the electrophilic character of the cyano group become reversed. As a result, two rings are simultaneously constructed by the nucleophilic attack of the amino group on the imino carbon and the subsequent attack of the imino nitrogen on the cyano group, yielding bicyclic product (34a) in $76 \%$ yield. 

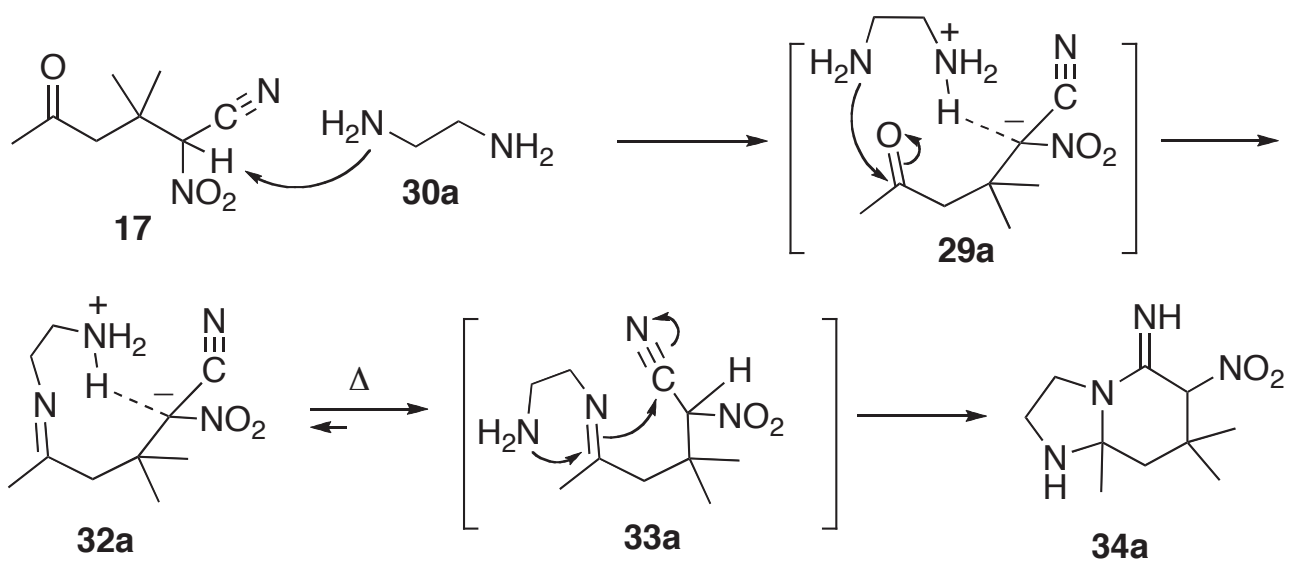

Scheme 18. A plausible mechanism for the tandem bicyclization of keto nitrile (17).

Table 6. Synthesis of diazabicyclic compounds (34 and 36) from keto nitrile (17) and diamines (30).

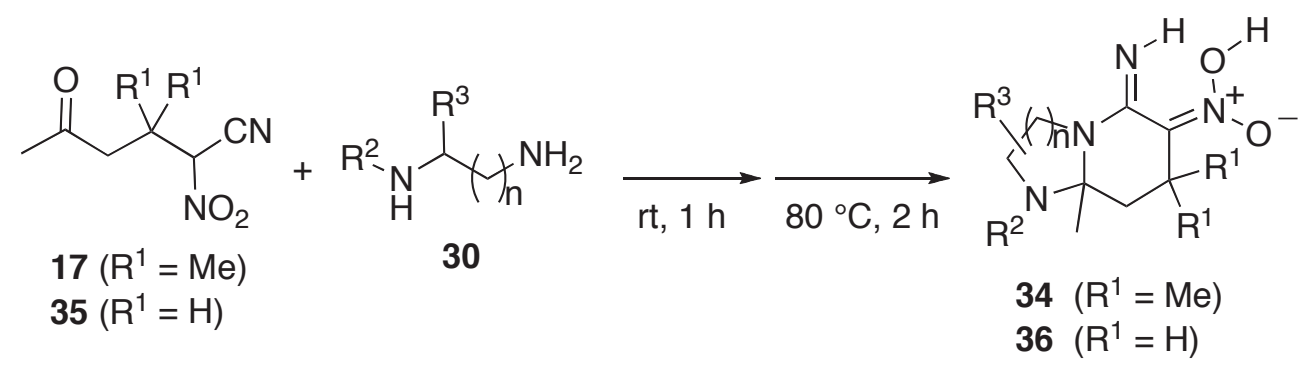

\begin{tabular}{cccccc}
\hline $\mathrm{R}^{1}$ & $\mathrm{R}^{2}$ & $\mathrm{R}^{3}$ & $\mathrm{n}$ & Product & Yield/\% \\
\hline $\mathrm{Me}$ & $\mathrm{H}$ & $\mathrm{H}$ & 1 & $\mathbf{3 4 a}$ & 76 \\
$\mathrm{H}$ & $\mathrm{H}$ & $\mathrm{H}$ & 1 & $\mathbf{3 6}$ & 26 \\
$\mathrm{Me}$ & $\mathrm{H}$ & $\mathrm{Me}$ & 1 & $\mathbf{3 4 b}, \mathbf{3 4 \mathbf { b } ^ { a }}$ & 65 \\
$\mathrm{Me}$ & $\mathrm{Et}$ & $\mathrm{H}$ & 1 & $\mathbf{3 4 c}$ & 79 \\
$\mathrm{Me}$ & $\mathrm{H}$ & $\mathrm{H}$ & 2 & $\mathbf{3 4 d}$ & 85 \\
$\mathrm{Me}$ & $\mathrm{H}$ & $\mathrm{H}$ & 3 & $\mathbf{3 4 e}$ & 23 \\
\hline
\end{tabular}

${ }^{a}$ A mixture of two regioisomers was formed in a 1:1 ratio.

The formation of $\mathbf{3 6}$ from $\mathbf{3 5}$ via bicyclization indicates that the presence of two methyl groups at the $\beta$-position of the $\delta$-keto nitrile is not required for this reaction. When 1,2-diaminopropane (30b) was employed, an equimolar mixture of regioisomers (34b and 34b') formed, indicating that the initial imination was unaffected by the presence of a methyl group on the ethylene chain. The reactivity of diamine (32c), which carries an $N$-ethyl group, was similar to that of the unsubstituted diamine (32a), and a bicyclic product (34c) was obtained, leading us to conclude that the $N$-ethyl group did not interfere with the reaction. This is noteworthy because it suggests that, in the present reaction, the primary amino group 
is preferred over the secondary amino group, even though they display similar basicity. It was furthermore possible to construct relatively large condensed rings by employing diamines (32d and 32e). Indeed, when using 1,3-diaminopropane (32d) was employed, bicyclization proceeded to afford diazabicyclo[4.4.0]decane (34d) in $85 \%$ yield. The use of 1,4-diaminobutane (32e) resulted in the formation of a seven-membered ring.

Though $\alpha$-nitro- $\delta$-keto nitrile (17) quantitatively affords 32a, $\delta$-keto nitrile (37), which does not carry a nitro group, remains unreacted, even after treatment with diamine (30a) under the same conditions as those used for the preparation of 32a (Scheme 19). This result indicates that the presence of a nitro group is prerequisite for the initial imination step. Because there are three carbons between the two functional groups (the cyano group and the keto group) in 17, the nitro group cannot activate the carbonyl group by an electron-withdrawing inductive effect. Therefore, the main role of the nitro group is to make the $\alpha$-hydrogen more acidic so that it can interact with diamine (30a) to form ammonium salt (32a), which is an essential step in triggering the pseudo-intramolecular process, as shown in Scheme 18.

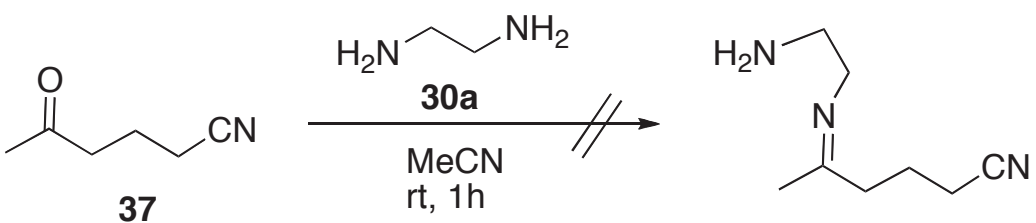

Scheme 19. Reaction of keto nitrile (37) with diamine (30a).

\section{SYNTHESIS OF BICYCLIC COMPOUND FROM $\alpha$-NITRO- $\delta$-KETO ESTER}

$\alpha$-Nitro- $\delta$-keto ester (38), which is easily prepared by the Michael addition of ethyl nitroacetate to chalcone, could also be employed as a substrate. Indeed, this compound also satisfies the two criteria to act as a substrate in the pseudo-intramolecular process. As expected, bicyclic compound (39) was precipitated in 64\% yield as a white solid from a solution of keto ester (38) and diamine (30a) in ethanol (Scheme 20). Thus, the present bicyclization method involving a pseudo-intramolecular process is not only applicable to $\alpha$-nitro- $\delta$-keto nitriles (17 and $\mathbf{3 5}$ ) but also to $\alpha$-nitro- $\delta$-keto ester (38).<smiles>CCOC(=O)C(C(CC(=O)c1ccccc1)c1ccccc1)[N+](=O)[O-]</smiles>

38<smiles>NCC[18OH]</smiles>

$$
\begin{array}{r}
\mathrm{EtOH} \\
\mathrm{rt}, 1 \mathrm{~d}
\end{array}
$$

$64 \%$

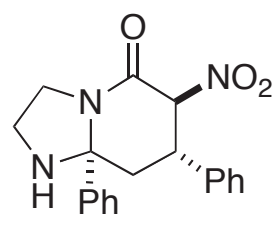

39

Scheme 20. Bicyclization reaction of keto ester (38) and diamine (30a). 


\section{CONCLUSION}

A reaction concept involving a pseudo-intramolecular process was developed and applied to the synthesis of polyfunctionalized heterocycles. Compounds that satisfied the two criteria -presence of an acidic hydrogen and additional functional group(s)- could serve as substrates in the present process. These requirements do not pose strict limitations on the substrate's molecular design and synthesis.

When a suitable substrate was allowed to react with an amine, an intimate pair formed via the intermediate ammonium salt, in which the nucleophilic amine and the electrophilic substrate are situated in proximity to each other. This spatial proximity enables an efficient reaction and proceeds as if it were an intramolecular process, even though it actually is an intramolecular process. Indeed, the reaction efficiently proceeds under mild conditions without forming considerable amounts of by-products. Furthermore, the steric congestion of the intimate pair makes the reaction sensitive to the bulkiness of the nucleophile, which enables reactions to be conducted in a regio- and chemoselective manner.

The present method can be conducted by simple manipulations, under air, without being affected by moisture, and affords multiply functionalized compounds that can be further converted into many new compounds. Hence, the pseudo-intramolecular reaction is expected to emerge as a powerful tool in the synthesis of polyfunctionalized compounds that cannot be prepared by alternative methods.

\section{REFERENCES}

1. M. Groppo, J. R. Pirani, M. L. F. Salatino, S. R. Blanco, and J. A. Kallunki, Am. J. Bot., 2008, 95, 985.

2. a) H. M. Hassanin and S. M. El-Edfawy, Heterocycles, 2012, 85, 2421; b) D. Audisio, S. Messaoudi, S. Cojean, J.-F. Peyrat, J.-D. Brion, C. Bories, F. Huteau, P. M. Loiseau, and M. Alami, Eur. J. Med. Chem., 2012, 52, 44; c) K.-i. Nakashima, M. Oyama, T. Ito, Y. Akao, J. R. Witono, D. Darnaedi, T. Tanaka, J. Murata, and M. Iinuma, Tetrahedron, 2012, 68, 2421; d) Y. Ikuma, H. Hochigai, H. Kimura, N. Nunami, T. Kobayashi, K. Uchiyama, Y. Furuta, M. Sakai, M. Horiguchi, Y. Masui, K. Okazaki, Y. Sato, and H. Nakahira, Bioorg. Med. Chem., 2012, 20, 5864.

3. a) H. Li, Y. Tang, and R. P. Hsung, Tetrahedron Lett., 2012, 53, 6138; b) F. M. Moghaddam, Z. Mirjafary, H. Saeidian, B. K. Foroushani, and S. Nourian, Synth. Commun., 2012, 42, 1941; c) A. Khodairy and M. Abass, Chem. Heterocycl. Compd., 2011, 47, 611.

4. N. Nishiwaki, Molecules, 2010, 15, 5174.

5. N. Nishiwaki, C. Tanaka, M. Asahara, N. Asaka, Y. Tohda, and M. Ariga, Heterocycles, 1999, 51, 567.

6. a) M. Asahara, C. Shibano, K. Koyama, M. Tamura, Y. Tohda, N. Nishiwaki, and M. Ariga, 
Tetrahedron Lett., 2005, 46, 7519; b) M. Asahara, M. Nagamatsu, Y. Tohda, N. Nishiwaki, and M. Ariga, J. Heterocycl. Chem., 2004, 41, 803.

7. N. Nishiwaki, A. Tanaka, M. Uchida, Y. Tohda, and M. Ariga, Bull. Chem. Soc. Jpn., 1996, 69, 1377.

8. M. Asahara, T. Katayama, Y. Tohda, N. Nishiwaki, and M. Ariga, Chem. Pharm. Bull., 2004, 52, 1334.

9. M. Asahara, M. Ohtsutsumi, M. Ariga, and N. Nishiwaki, Heterocycles, 2009, 78, 2851.

10. M. Asahara, M. Ohtsutsumi, M. Tamura, N. Nishiwaki, and M. Ariga, Bull. Chem. Soc. Jpn., 2005, 78, 2235.

11. N. Nishiwaki, M. Sakashita, M. Azuma, C. Tanaka, M. Tamura, N. Asaka, K. Hori, Y. Tohda, and M. Ariga, Tetrahedron, 2002, 58, 473.

12. a) N. Aljaar, C. C. Malakar, J. Conrad, S. Strobel, T. Schleid, and U. Beifuss, J. Org. Chem., 2012, 77, 7794; b) R. Rüttinger, J. Leutzow, M. Wilsdorf, K. Wilckens, and C. Czekelius, Org. Lett., 2011, 13, 224; c) M. Kidwai, S. Bhardwaj, and R. Poddar, Beilstein J. Org. Chem., 2010, 6, No. 35; d) I. Ullah, M. Sher, R. A. Khera, A. Ali, M. Nawaz, M. Shkoor, I. Iqbal, M. Imran, A. Villinger, C. Fischer, and P. Langer, Tetrahedron, 2010, 66, 3824; e) Y. Jiang, N. Wu, H. Wu, and M. He, Synlett, 2005, 2731.

13. a) Z. Huang and J. F. Hartwig, Angew. Chem. Int. Ed., 2012, 51, 1028; b) J. A. Cadieux, Z. Zhang, M. Mattice, A. Brownlie-Cutts, J. Fu, L. G. Ratkay, R. Kwan, J. Thompson, J. Sanghara, J. Zhong, and Y. P. Goldberg, Bioorg. Med. Chem. Lett., 2012, 22, 90; c) B. Lu, B. Wang, Y. Zhang, and D. Ma, J. Org. Chem., 2007, 72, 5337; d) J. G. Zeevaart, C. J. Parkinson, and C. B. de Koning, Tetrahedron Lett., 2007, 48, 3289; e) J. G. Zeevaart, C. J. Parkinson, and C. B. de Koning, Tetrahedron Lett., 2004, 45, 4261; f) D. H. R. Barton, J.-C. Blazejewski, B. Charpiot, J.-P. Finet, W. B. Motherwell, M. T. B. Papoula, and S. P. Stanforth, J. Chem. Soc., Perkin Trans. 1, 1985, 2667.

14. G. E. Hall, D. Hughes, D. Rae, and A. P. Rhodes, Tetrahedron Lett., 1967, 8, 241.

15. M. P. Egorov, V. K. Bel'skii, É. S. Petrov, M. I. Terekhova, and I. P. Beletskaya, J. Org. Chem. U. S. S.R., 1985,1855 .

16. N. Nishiwaki, D. Nishida, T. Ohnishi, F. Hidaka, S. Shimizu, M. Tamura, K. Hori, Y. Tohda, and M. Ariga, J. Org. Chem., 2003, 68, 8650.

17. Recent review for retro-Claisen condensation. M. Jukič, D. Šterk, and Z. Časar, Curr. Org. Synth., $2012,9,488$.

18. a) A. J. Clark, C. P. Dell, J. M. McDonagh, J. Geden, and P. Mawdsley, Org. Lett., 2003, 5, 2063; b) R. V. Hoffman and S. Madan, J. Org. Chem., 2003, 68, 4876; c) A. Luna, I. Alfonso, and V. Gotor, Org. Lett., 2002, 4, 3627.

19. Ethyl chloroformylacetate has also been prepared from symmetrical diethyl malonate by selective chemical conversion. a) M. Fonvielle, H. Therisod, M. Hemery, and M. Therisod, Bioorg. Med. 
Chem. Lett., 2007, 17, 410; b) V. G. S. Box, N. Marinovic, and G. P. Yiannikouros, Heterocycles, 1991, 32, 245; c) T. Kametani, T. Katoh, M. Tsubuki, and T. Honda, Chem. Pharm. Bull., 1985, 33, 61.

20. A. Miller, J. Org. Chem., 1976, 41, 3599.

21. Z. Bánkowska, I. Zadrozna, and D. Stopa, Pol. J. Chem., 1979, 53, 1563.

22. Y. Nakaike, N. Taba, S. Itoh, Y. Tobe, N. Nishiwaki, and M. Ariga, Bull. Chem. Soc. Jpn., 2007, 80, 2413.

23. A. L. Laikhter, V. P. Kislyi, and V. V. Semenov, Mendeleev Commun., 1993, 20.

24. R. Ballini, G. Bosica, and D. Fiorini, Tetrahedron, 2003, 59, 1143.

25. Synthesis of cyano-aci-nitroacetate: N. Nishiwaki, Y. Takada, Y. Inoue, Y. Tohda, and M. Ariga, J. Heterocycl. Chem., 1995, 32, 473.

26. Synthesis of glutaronitriles: N. Nishiwaki, T. Nogami, C. Tanaka, F. Nakashima, Y. Inoue, N. Asaka, Y. Tohda, and M. Ariga, J. Org. Chem., 1999, 64, 2160.

27. Synthesis of isoxazolines: N. Nishiwaki, T. Nogami, T. Kawamura, N. Asaka, Y. Tohda, and M. Ariga, J. Org. Chem., 1999, 64, 6476.

28. Synthesis of aminals and oximes: N. Nishiwaki, Y. Okajima, M. Tamura, N. Asaka, K. Hori, Y. Tohda, and M. Ariga, Heterocycles, 2003, 60, 303.

29. Generation of nitrile oxides: a) N. Nishiwaki, K. Kobiro, S. Hirao, J. Sawayama, K. Saigo, Y. Ise, M. Nishizawa, and M. Ariga, Org. Biomol. Chem., 2012, 10, 1987; b) N. Nishiwaki, K. Kobiro, S. Hirao, J. Sawayama, K. Saigo, Y. Ise, Y. Okajima, and M. Ariga, Org. Biomol. Chem., 2011, 9, 6750; c) N. Nishiwaki, K. Kobiro, H. Kiyoto, S. Hirao, J. Sawayama, K. Saigo, Y. Okajima, T. Uehara, A. Maki, and M. Ariga, Org. Biomol. Chem., 2011, 9, 2832; d) N. Nishiwaki, T. Uehara, N. Asaka, Y. Tohda, M. Ariga, and S. Kanemasa, Tetrahedron Lett., 1998, 39, 4851.

30. Synthesis of pyrroles: N. Nishiwaki, M. Nakanishi, T. Hida, Y. Miwa, M. Tamura, K. Hori, Y. Tohda, and M. Ariga, J. Org. Chem., 2001, 66, 7535.

31. Synthesis of keto nitrile (17): N. Nishiwaki, T. Nogami, and M. Ariga, Heterocycles, 2008, 75, 675.

32. N. Nishiwaki, K. Kakutani, M. Tamura, and M. Ariga, Chem. Lett., 2009, 38, 680.

33. a) V. J. Ram, N. Agarwal, A. Sharon, and P. R. Maulik, Tetrahedron Lett., 2002, 43, 307; b) M. R. Bryce, J. Mater. Chem., 2000, 10, 589; c) M. S. Wong, C. Bosshard, F. Pan, and P. Günter, Adv. Mater., 1996, 8, 677.

34. S. Hirao, K. Kobiro, J. Sawayama, K. Saigo, and N. Nishiwaki, Tetrahedron Lett., 2012, 53, 82.

35. N. Nishiwaki, S. Hirao, J. Sawayama, K. Saigo, and K. Kobiro, Chem. Commun., 2011, 47, 4938. 


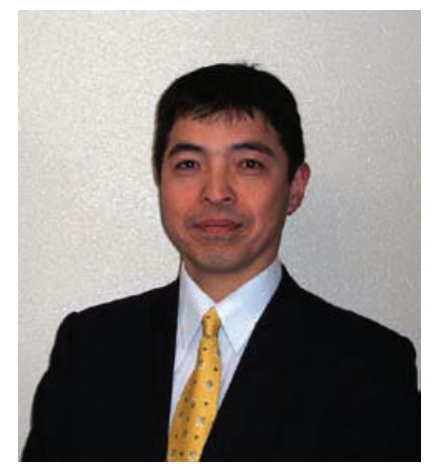

Professor Nagatoshi Nishiwaki received his Ph. D. in 1991 from Osaka University. He worked at Professor Ariga's group in Department of Chemistry, Osaka Kyoiku University, as assistant professor (1991-2000) and as associate professor (2001-2008). From 2000 to 2001, he joined to Karl Anker Jørgensen's group at Århus University in Denmark. He worked at Center for Collaborative Research, Anan National College of Technology as associate professor from 2008 to 2009. Then, he moved to School of Environmental Science and Engineering, Kochi University of Technology in 2009, and he is a professor from 2011. His research interests comprise synthetic organic chemistry using nitro compounds, heterocycles (synthesis, ring transformation, 1,3-dipolar cycloaddition, application as tools in organic synthesis), pseudo-intramolecular reaction, and solid supported palladium catalysts. 